\title{
Avaliação ergonômica do trabalho emindústria de aço inox: análise de condições psicofisiológicas
}

\author{
Ergonomic evaluation of the stainless steel industry: \\ analysis of psycho physiological conditions \\ Maria Hilda Araújo Ribeiro', Graça de Fátima Pereira Almeida², \\ Marcos Antonio Custódio Neto da Silva ${ }^{3}$, Rebeca Costa Castelo Branco ${ }^{3}$, \\ Flávia Coelho Mohana Pinheiro ${ }^{4}$, Maria do Desterro Soares Brandão Nascimento ${ }^{1}$
}

\begin{abstract}
RESUMO | Contexto: Apresenta-se um método de intervenção ergonômica, em que são investigadas as condições psicofisiológicas do trabalho de operários em postos de trabalho em indústria de aço inox. Objetivo: Avaliar as condições de trabalho e propor sugestões que viabilizem um ambiente de trabalho ergonômico. Métodos: Estudo descritivo e retrospectivo obtido a partir de levantamento de dados de 47 funcionários oriundos de uma metalúrgica de aço inox, em São Luís, Maranhão, no período de janeiro a dezembro de 2011, através de visita técnica. Resultados: Nos postos de trabalhos observados neste estudo, o tipo de tarefa exercida é de livre postura, ora estando em pé, ora estando sentado ou semissentado. O tipo de banco utilizado é questionável, pois não possui nenhum encosto. Os problemas observados foram: acidentário e arquitetural, devido à falta de planejamento de espaços e ambientação agradáveis ao trabalho; biológico, pela sujeira acumulada e não adequação às normas de higiene; físico-ambiental, pela falta de iluminação suficiente para execução principalmente de trabalhos que requerem precisão; interfacial, sendo observadas as bancadas de trabalho e principalmente os bancos sem qualquer tipo de apoios para execução das tarefas; químico-ambiental, pela falta de limpeza no local de trabalho, expondo diariamente o trabalhador a substâncias pesadas prejudiciais à saúde. Conclusão: A pesquisa demonstra a fragilidade das condições de trabalho em uma empresa de São Luís. É importante realizar mudanças com vistas à garantia de melhores condições de serviço, de acordo com a ergonomia.
\end{abstract}

Palavras-chave I exames médicos; engenharia humana; trabalho.

\begin{abstract}
I Context: We present a method for ergonomic intervention, in which the psychophysiological work conditions of workers in the stainless steel industry are investigated. Objective: To assess the working conditions and provide suggestions to enable an ergonomic work environment. Methods: This was a descriptive, retrospective study obtained from survey data of 47 employees from a stainless steel smelter in São Luís, Maranhão, Brazil, from January to December 2011, trough technical visit. Results: In the workstations observed in this study, the body posture is free posture, sometimes in standing position, sitting or semi-sitting. The type of bank used is questionable, as there is no backrest. The observed problems were: accidental and architectural, due to the lack of planning space and pleasant work environment; biological, due to accumulated dirt and non-compliance with hygiene standards; physical and environmental, due to the lack of sufficient lighting especially in jobs requiring precision; interfacial, with work benches and especially banks without any kind of support for the execution of tasks; chemical and environmental, due to the lack of a clean workplace, exposing the worker to heavy substances harmful to health on a daily basis. Conclusion: The study shows the fragility of working conditions at a company in São Luís. It is important to make changes in order to guarantee better conditions of service, according to ergonomic principles.
\end{abstract}

Keywords I medical examination; human engineering; work.

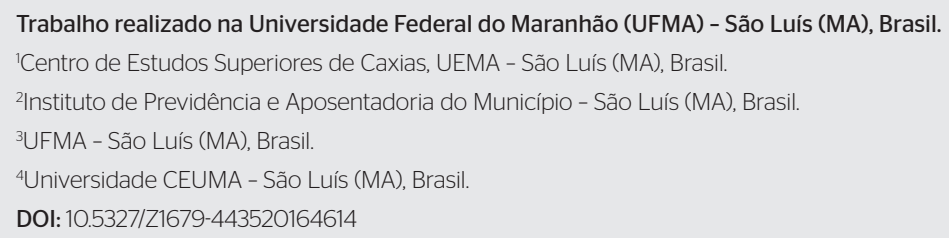




\section{INTRODUÇÃO}

O setor da indústria metalúrgica representa um importante componente da economia mundial, empregando cerca de 70 milhões de pessoas em todo o mundo ${ }^{1}$. No Brasil, em novembro de 2010, o ramo metalúrgico respondeu por $5,2 \%$ do total de ocupados e por $26,4 \%$ do emprego industrial ${ }^{2}$.

A partir da Revolução Industrial, as tecnologias evoluíram e ocorreram modificações significativas nas relações de trabalho, objetivando o aumento da produtividade e o desenvolvimento do capitalismo. Ao longo do tempo, disfunções ocorrem no processo produtivo de trabalho, gerando aumento da carga física e mental dos trabalhadores.

A ergonomia é uma ciência interdisciplinar. Ela compreende a fisiologia e a psicologia do trabalho, bem como a antropometria e a socialização no trabalho. O objetivo prático da ergonomia é a adaptação do posto de trabalho, dos instrumentos, das máquinas, dos horários e do meio ambiente às exigências do homem. A realização de tais objetivos, em nível industrial, propicia uma facilidade e um rendimento do esforço humano ${ }^{3}$. Outro aspecto da ergonomia evidenciado para a melhoria do trabalho humano é o estudo do ambiente no qual o trabalho é realizado, essa é a área da ergonomia do ambiente construído. As situações de risco e segurança nos espaços arquitetônicos e nas cidades têm possibilitado aos ergonomistas uma reflexão sobre o que pode ser melhorado e uma busca por soluções ${ }^{3}$.

A ergonomia é uma disciplina que promove uma abordagem holística e centrada no ser humano para o design de sistemas de trabalho que considera relevantes os fatores físicos, cognitivos, sociais, organizacionais e ambientais ${ }^{4-6}$.

Um dos aspectos nos quais a ergonomia atua visando à melhoria do trabalho humano é a prevenção de riscos e custos humanos do trabalho. Para a ergonomia, o risco compreende uma percepção multidimensional, envolvendo fatores psicológicos, sociais e culturais ${ }^{7}$.

Segundo o Manual de Aplicação da Norma Regulamentadora no 17 , de 2002, a análise ergonômica do trabalho (AET) é um processo construtivo e participativo para a resolução de um problema complexo que exige o conhecimento das tarefas, da atividade desenvolvida para realizá-las e das dificuldades enfrentadas para se atingir o desempenho e a produtividade exigidos ${ }^{8}$.
No Brasil, as empresas estão abarcando a ergonomia com grande ênfase para, além de facilitar a interação entre o homem e o trabalho, permitir que o ambiente de trabalho seja favorável à execução das tarefas e benéfico aos colaboradores. No país, as organizações enfrentam muitos problemas como: ritmo acelerado de trabalho para garantir a produção, trabalho fragmentado (em que cada um exerce uma única tarefa de forma repetitiva), ambientes quentes, ruidosos, mal ventilados e com mobiliário inadequado. Todos esses problemas geram distúrbios psicológicos e fisiológicos e provocam sérios danos à saúde, como a lesão por esforço repetitivo (LER) e os distúrbios osteomusculares relacionados ao trabalho (DORT), que comprometem a produtividade, a saúde e a segurança.

A intervenção ergonômica apresenta-se como um método no qual são investigadas as condições psicofisiológicas do trabalho de operários em postos de trabalho da indústria de aço inox em São Luís, Maranhão. Com a multidisciplinaridade da ergonomia, e por meio de visitas técnicas e laudos periciais obtidos a partir de observações e entrevistas, realizadas nessa empresa, são demonstrados resultados preliminares para possíveis ajustes e modificações no ambiente operacional, visando proporcionar sempre a integridade e o bem-estar do trabalhador em foco. Com esse entendimento, afirma-se a importância da aplicação da ergonomia nos postos de trabalho de operários em metalúrgicas, com o objetivo de empreender a análise dos problemas que atuam diretamente para a instabilidade física e cognitiva do trabalhador?.

No Brasil, vários estudos têm sido desenvolvidos acerca da ergonomia, mas poucos em relação à indústria metalúrgica. Neste trabalho, realizamos uma intervenção ergonomizadora em metalúrgica de aço inox: apreciação ergonômica, para fins de perícias médicas após uma visita técnica para verificação das condições no ambiente de trabalho. A partir daí, sugerimos melhorias no local de trabalho, fazendo com que essas medidas possam contribuir para a prevenção de doenças relacionadas ao trabalho, visando reduzir absenteísmos, afastamentos e pendências jurídicas ${ }^{10}$. Objetivou-se propor sugestões de melhorias aos operários, no que se refere à segurança de trabalho e à manutenção de posturas assumidas nas atividades realizadas, e sugestões que viabilizem novos equipamentos para execução dos trabalhos. 


\section{MÉTODOS}

Para poder analisar as capacidades, as limitações e a ergonomia de um processo produtivo, visando torná-lo mais viável e facilitador para a organização, fundamentamos o presente estudo com base em observações in loco e em instrumentos metodológicos, como entrevistas, leituras, pesquisas bibliográficas, orientações em sala e diagnóstico para facilitar o levantamento de dados. Foram aplicados questionários baseados na escala de Likert e realizada pesquisa de campo para realização de um estudo de caso.

A escala de Likert é uma ferramenta de resposta psicométrica usada comumente em questionários, sendo a mais usada em pesquisas de opinião. Ao responderem a um questionário baseado nessa escala, os respondentes especificam seu nível de concordância com uma afirmação. Os participantes responderam ao questionário de acordo com as seguintes afirmações: (1) discordo totalmente; (2) discordo; (3) indeciso; (4) concordo; (5) concordo totalmente.

Foi realizada uma análise ergonômica do trabalho em indústria de aço inox, segundo a metodologia de Wisner. Para ele, esta se divide em: análise da demanda; exame das condições técnicas, econômicas e sociais; análise das atividades - elemento central do estudo; diagnóstico; recomendações; simulação do trabalho com as modificações propostas; avaliação do trabalho na nova situação ${ }^{11}$.

Seguindo a metodologia de Wisner, a análise ergonômica do trabalho consiste em três etapas. Na primeira é feita uma análise das referências bibliográficas sobre o homem em atividade de trabalho, bem como a respeito do objeto de estudo a ser desenvolvido. A segunda etapa, a análise ergonômica do trabalho propriamente dita, é constituída de três fases: análise da demanda, análise da tarefa e análise das atividades. A terceira etapa consiste na síntese ergonômica do trabalho, subdividida em duas fases: estabelecimento do diagnóstico da situação de trabalho; e elaboração do caderno de encargos de recomendações ergonômicas ${ }^{11}$.

Trata-se de um estudo descritivo e retrospectivo obtido a partir de levantamento de dados de registro de prontuários de 47 funcionários, do sexo masculino, com idade entre 20 e 55 anos, oriundos de uma metalúrgica de aço inox, localizada em São Luís, Maranhão, no período de janeiro a dezembro de 2011. Este trabalho buscou descrever as atividades de operários em postos de trabalho em uma metalúrgica, bem como classificar os constrangimentos ergonômicos em suas atividades a fim de obter resultados satisfatórios na intervenção ergonômica, por meio de visita técnica.

\section{RESULTADOS}

A intervenção sobre os ambientes e as condições de trabalho deve basear-se em uma análise criteriosa e global da organização do trabalho, que inclui a análise ergonômica do trabalho real da atividade, do conteúdo das tarefas, dos modos operatórios, dos postos de trabalho, do ritmo e da intensidade do trabalho, dos fatores mecânicos, das condições físicas do posto de trabalho, das normas de produção, dos sistemas de turnos, dos fatores psicossociais e individuais e da relação de trabalho entre colegas e chefias. Além disso, contempla as medidas de proteção coletiva e individual implementadas pelas empresas e as estratégias de defesa individuais e coletivas adotadas pelos trabalhadores.

A ergonomia é uma ciência interdisciplinar. Compreende a fisiologia e a psicologia do trabalho, bem como a antropometria e a sociedade no trabalho. $\mathrm{O}$ objetivo prático da ergonomia é a adaptação do posto de trabalho, dos instrumentos, das máquinas, dos horários e do meio ambiente às exigências do homem. A realização de tais objetivos, em nível industrial, propicia uma facilidade e um rendimento do esforço humano.

Para a composição deste trabalho fizemos uma visita técnica com a finalidade de estudar as condições de trabalho na empresa objeto de estudo. O que se pode observar, com base na Norma Regulamentadora ${ }^{\circ} 17$, que trata de ergonomia, foi que havia inúmeras não conformidades do ponto de vista organizacional, arquitetural, biológico, químico e de higiene ocupacional.

Na visita técnica para fins de perícia, pudemos observar o relacionamento empregador/empregado nessa problematização, supondo que o empregador desconhece e/ou omite algumas condições básicas nos postos de trabalho em relação à segurança do empregado que, por sua vez, não tem o cuidado de manter o uso de equipamentos de segurança e/ou desconhece regras e meios para a aplicação do trabalho seguro. 
$\mathrm{Na}$ visita técnica aos postos de trabalho observados neste estudo, o tipo de tarefa exercida é de livre postura, ora estando em pé, ora estando sentado ou semissentado, pois se trata de um trabalho não linear, que varia de acordo com o tipo do projeto de produto. $\mathrm{O}$ tipo de banco adotado na metalúrgica estudada é questionável, pois não possui nenhum encosto, sem falar na bancada, que é fixa, imóvel a qualquer ajuste.

A partir das observações feitas na indústria metalúrgica de aço inox, foram detectadas reclamações de dores e fadigas musculares pelo fato de os trabalhadores assumirem, na operação da tarefa, posturas viciosas por longos períodos, bem como por tentarem manter uma postura agradável em momentos que fazem bastante esforço com altas cargas de materiais.

$\mathrm{Na}$ visita técnica aos postos de trabalho da pesquisa foram detectados e reconhecidos problemas de diversas ordens, sendo delimitados como principais problemas observados: acidentário e arquitetural, biológico, cognitivo, informacional, interfacial, físico-ambiental e químico-ambiental. A Figura 1 apresenta a formulação ilustrada da problematização.

Muitos problemas são observados e saltam aos olhos no local da intervenção, porém, os mais relevantes destacados nesta pesquisa são:

- acidentário e arquitetural, devido à falta de planejamento de espaços e ambientação agradável ao trabalho, deixando os locais desorganizados, com materiais expostos nas passagens, além da indiferença, por parte dos trabalhadores, em relação ao uso de equipamentos de proteção;

- biológico, pela sujeira acumulada e não adequação às normas de higiene;

- físico-ambiental, pela falta de iluminação suficiente para execução, principalmente, de trabalhos que requerem precisão;

- interfacial, sendo observadas bancadas de trabalho e principalmente bancos sem qualquer tipo de apoio para execução das tarefas;

- químico-ambiental, pela falta de limpeza no local de trabalho, expondo diariamente o trabalhador a substâncias pesadas prejudiciais à saúde.

A partir dessas observações, foi elaborado um quadro -resumo apontando os problemas identificados e as sugestões para a resolução (Quadro 1).

\section{DISCUSSÃO}

O presente estudo teve o objetivo de estabelecer a importância da ergonomia na realização das perícias médicas, mostrando diferentes conceitos que guiam sempre para a necessidade de haver a interdisciplinaridade na avaliação e discussão das práticas das atividades laborais em um ambiente de trabalho.

O campo de atuação da ergonomia abrange a perfeita adequação do trabalho, da técnica e do meio ambiente ao trabalhador, ou seja, objetiva a plena interação homem-máquina.

Segundo Soares ${ }^{12}$, a principal meta da ergonomia é o projeto de sistemas de tal modo que eles se tornem produtivos, seguros e, talvez, mais confortáveis e agradáveis.

$O$ atual perfil de saúde da população é fruto das profundas transformações sociais e econômicas ocorridas nas últimas décadas ${ }^{13}$. Aplicando esse conhecimento ao trabalho de metalúrgicos, devem ser considerados todos os seus múltiplos aspectos, desde o recrutamento e a seleção até a formação dos trabalhadores, respeitando sempre as suas características psicofisiológicas.

Dada a inegável e consciente importância da ergonomia no universo de segurança e saúde no trabalho, o Ministério do Trabalho e da Previdência Social (MTPS), por meio da Portaria no 3.751, de 23 de novembro de $1990^{8}$, procedeu a uma reestruturação da Norma Regulamentadora no 17 Ergonomia, ampliando os seus tópicos de abordagem para: - levantamento, transporte e descarga individual de materiais;

- mobiliários dos postos de trabalho;

- condições ambientais de trabalho;

- organização do trabalho.

Conforme Dul e Weerdmeester ${ }^{14}$, a partir do estudo da biomecânica, o transporte e/ou o levantamento de cargas devem ser feitos com o material o mais próximo possível do corpo, pois aumentar a distância entre as mãos e o corpo gera aumento de tensões nas costas. Como na indústria metalúrgica os insumos são geralmente pesados, a observação do limite para as movimentações de cargas é um importante fator de estudo.

Com relação à iluminação, as superfícies de trabalho, as paredes e os pisos devem ser foscos, é recomendado que se equilibre as luminâncias usando cores suaves. Os coeficientes de reflexão das superfícies do ambiente devem estar 


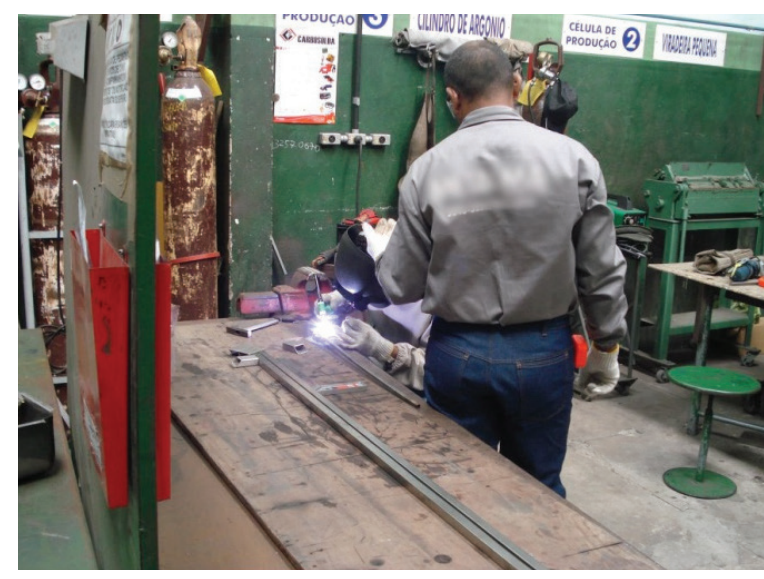

Acidentário: Falta de proteção para os olhos

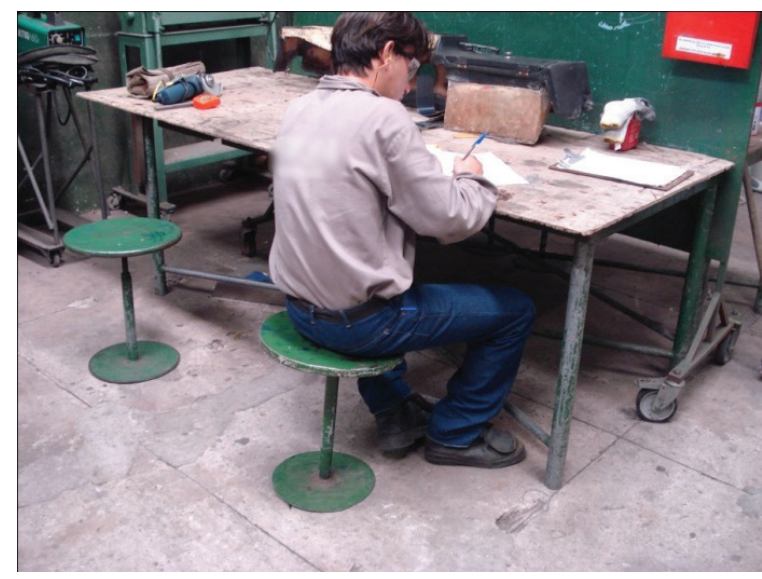

Interfacial: Má postura assumida por causa do banco

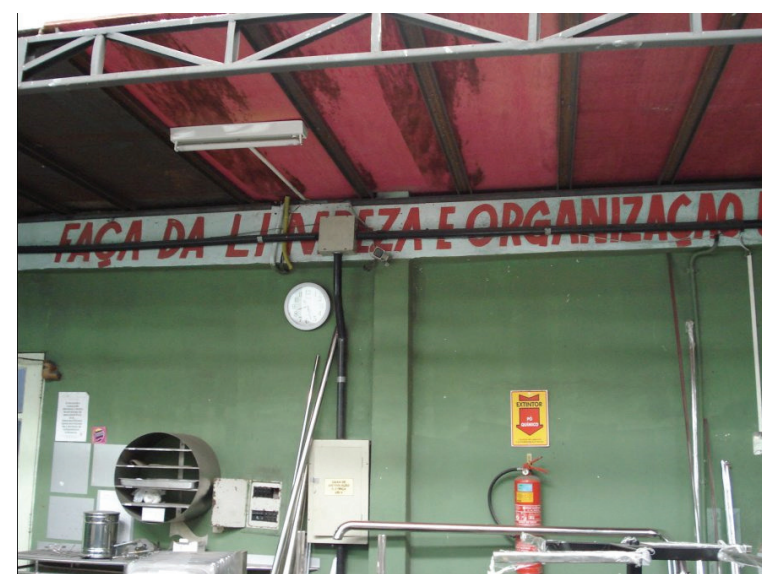

Informacional: Equipamentos em sobreposição de letreiro

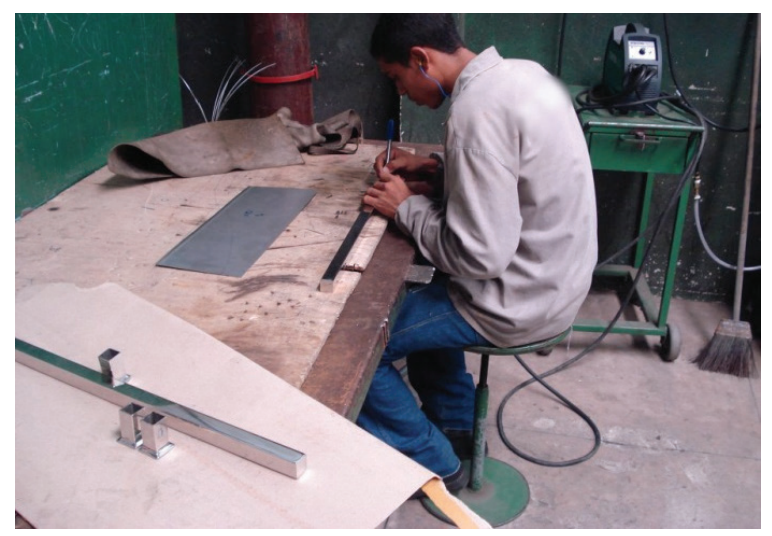

Interfacial: Má postura assumida por causa do banco

Físico-ambiental: Pouca iluminação, e a existente causa área de sombras

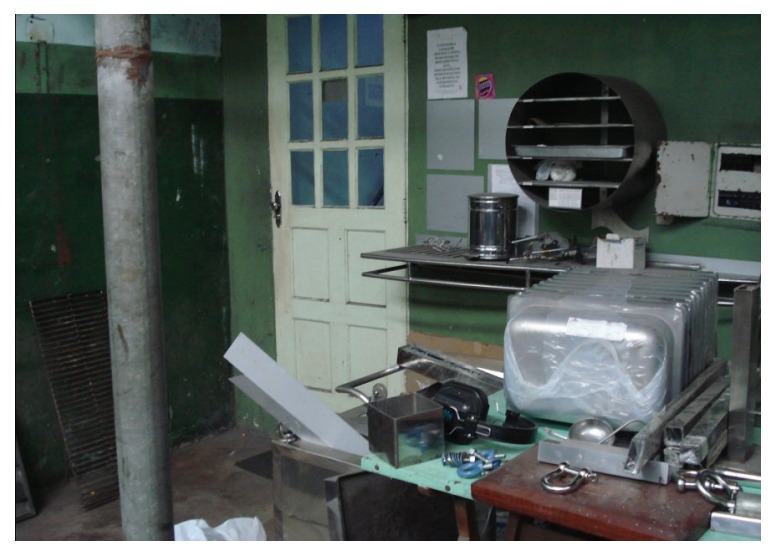

Arquitetural: Falta de local definido para estoque e guarda de materiais Acidentário: Chapas de aço com cantos vivos expostos na passagem

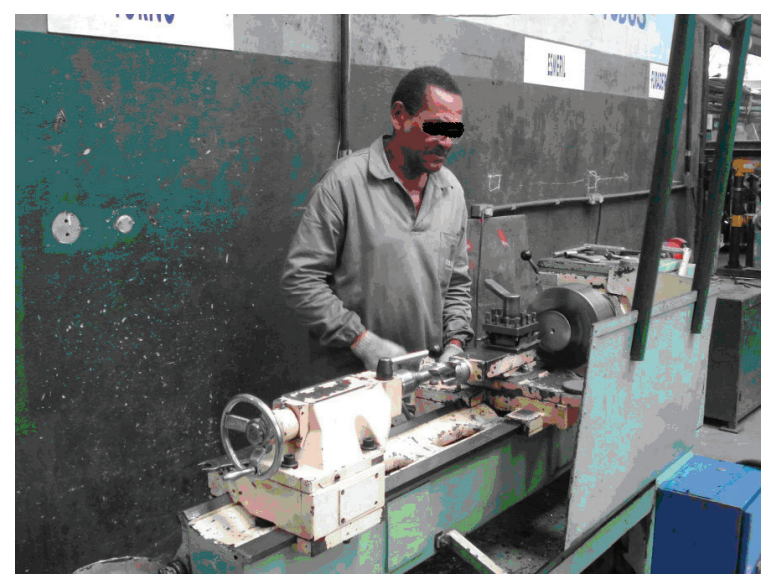

Acidentário: Falta de equipamento de proteção individual (EPI)

Figura 1. Formulação ilustrada da problematização. 


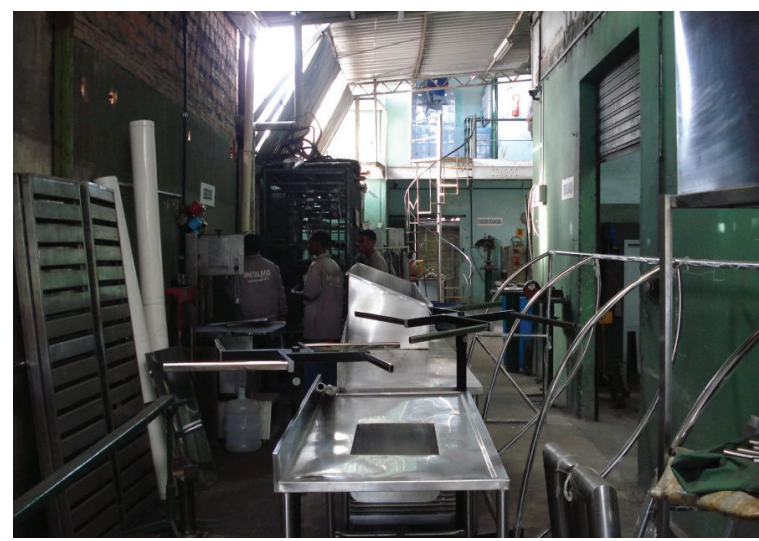

Arquitetural: Falta de local definido para estoque e guarda de materiais Acidentário: Materiais e produtos expostos na passagem

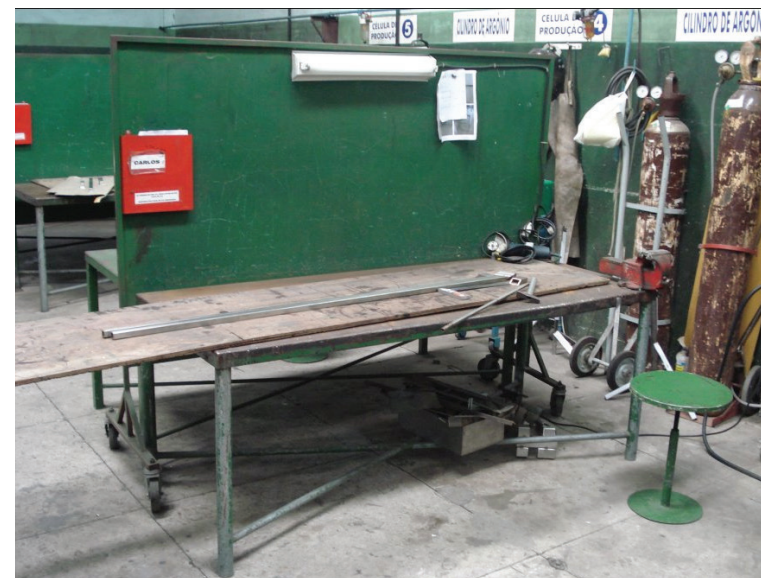

Acidentário: Peça de madeira improvisada para extensão da mesa

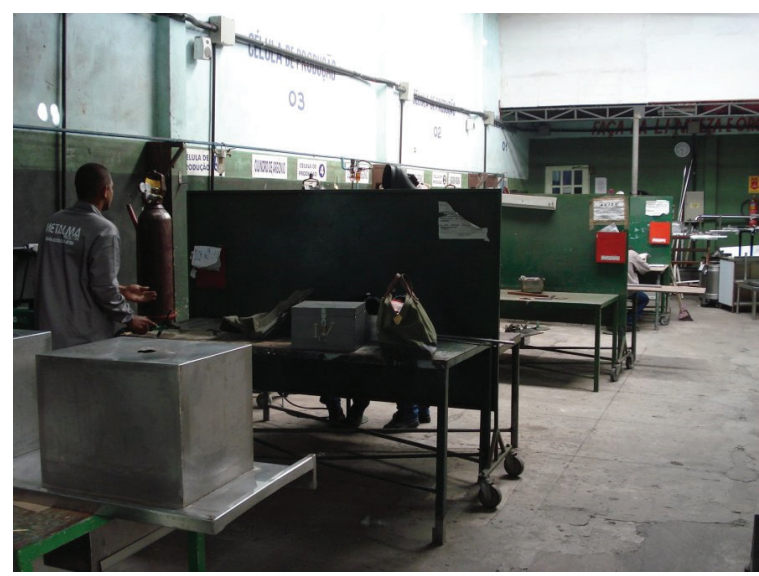

Físico-ambiental: Pouca iluminação, e a existente causa área de sombras

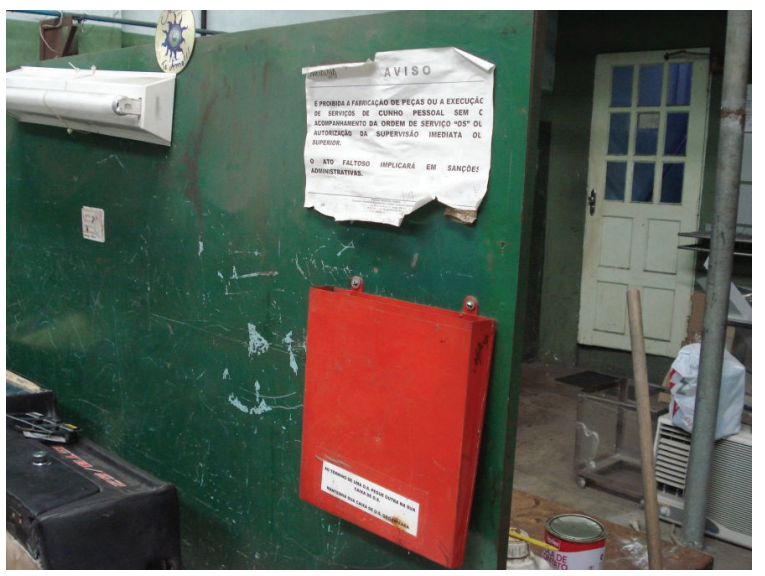

Cognitivo: Texto com linguagem muito elevada para interpretação

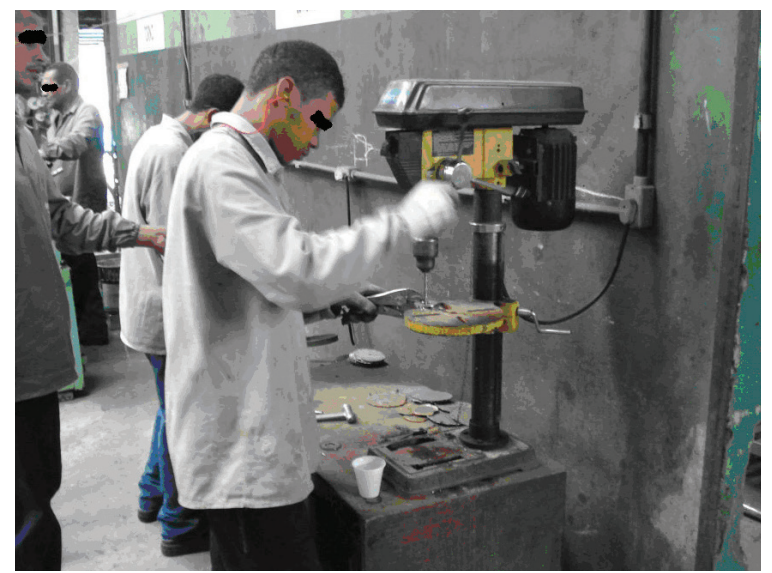

Acidentário: Falta de equipamento de proteção individual (EPI)

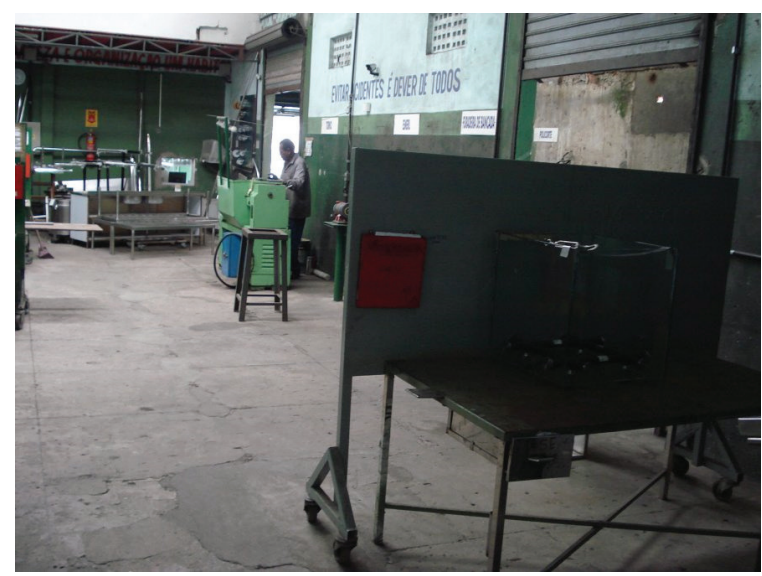

Físico-ambiental: Pouca iluminação, e a existente causa área de sombras

Figura 1. Continuação. 


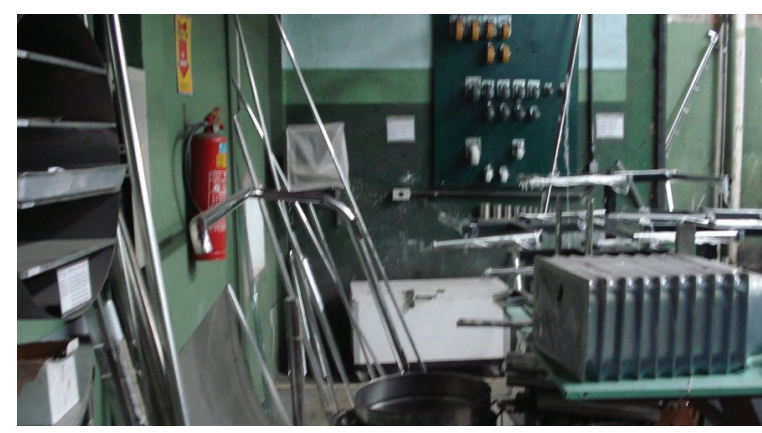

Acidentário: Materiais e produtos expostos na passagem para acesso ao extintor de incêndio

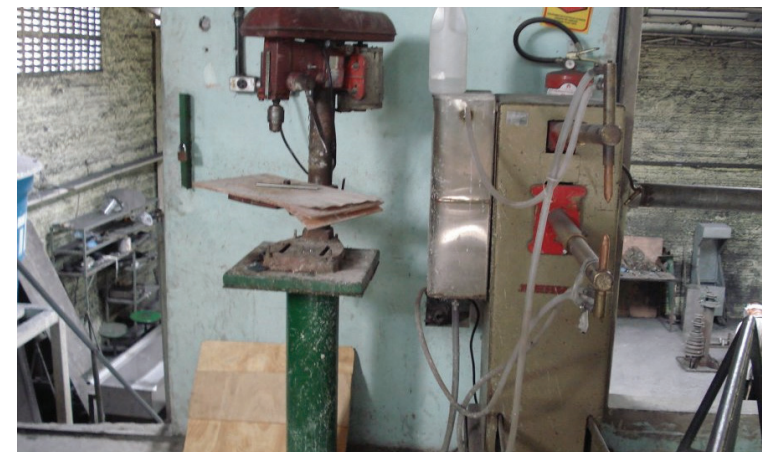

Acidentário: Máquina obstruindo o acesso ao extintor de incêndio

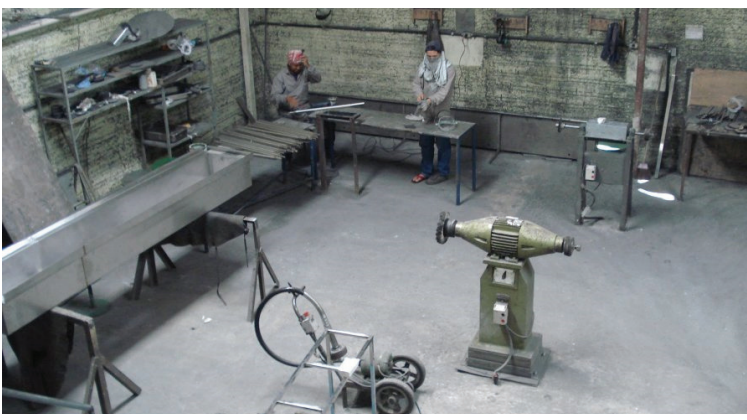

Químico-ambiental: Resíduos químicos acumulados Biológico: Sujeira acumulada

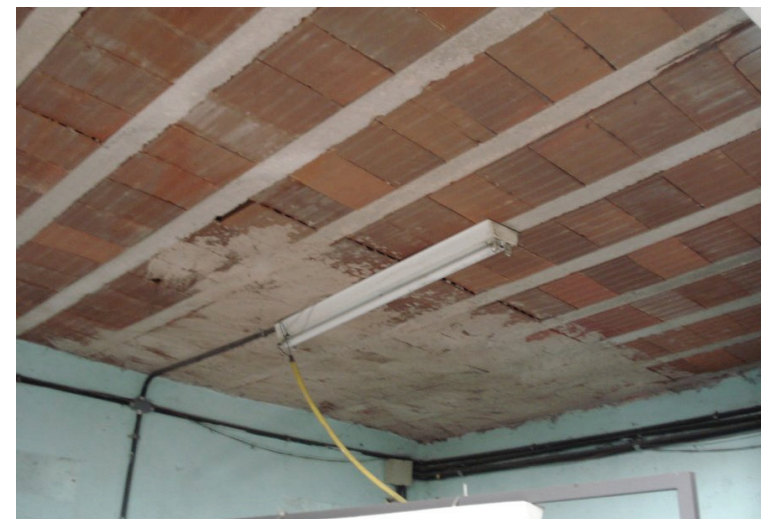

Acidentário: Conexões expostas

Arquitetural: Local não acabado

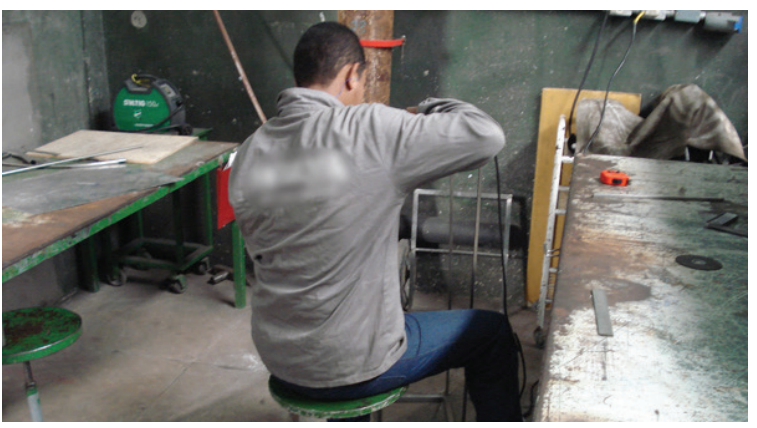

Acidentário: Falta de equipamento de proteção individual (EPI) Interfacial: Má postura assumida por causa do banco

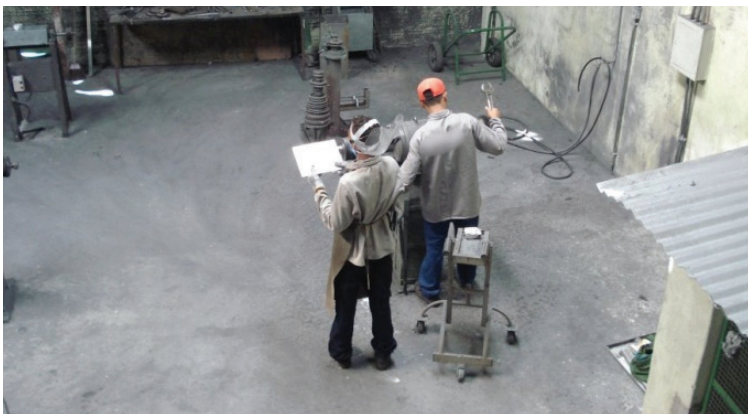

Químico-ambiental: Resíduos químicos acumulados Biológico: Sujeira acumulada

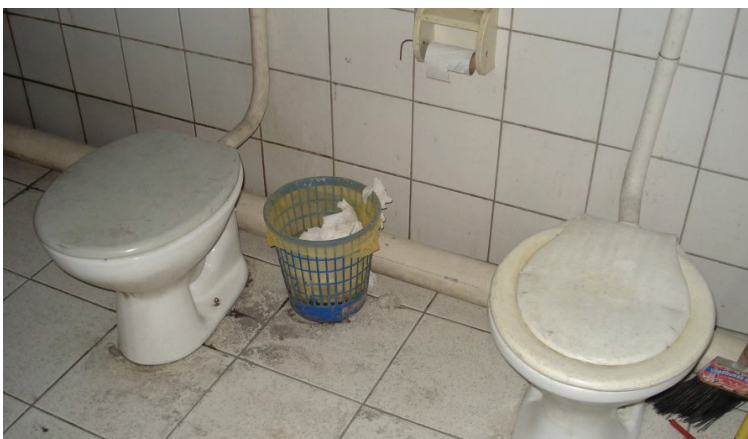

Biológico: Sujeira acumulada

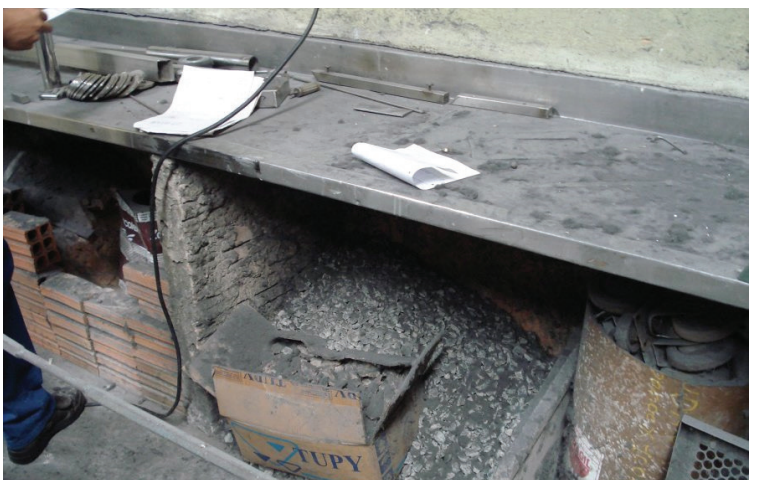

Químico-ambiental: Resíduos químicos acumulados

Biológico: Sujeira acumulada

Arquitetural: Falta de local definido para estoque e guarda de materiais

Figura 1. Continuação. 
Quadro 1. Quadro de formulação dos problemas.

\begin{tabular}{|c|c|c|c|c|c|c|}
\hline $\begin{array}{l}\text { Classe de } \\
\text { problemas }\end{array}$ & Requisitos & Constrangimentos & Custos humanos & $\begin{array}{l}\text { Disfunções do } \\
\text { sistema }\end{array}$ & Sugestões & Restrições \\
\hline \multicolumn{7}{|c|}{ Interfacial } \\
\hline $\begin{array}{l}\text { Flexão cons- } \\
\text { tante do } \\
\text { tronco nos } \\
\text { trabalhos } \\
\text { sentado }\end{array}$ & $\begin{array}{l}\text { Apoio nos } \\
\text { bancos }\end{array}$ & $\begin{array}{l}\text { Posturas pouco } \\
\text { confortáveis, para } \\
\text { compensar o } \\
\text { tipo de assento } \\
\text { utilizado }\end{array}$ & $\begin{array}{c}\text { Pode ocasionar } \\
\text { lesões e dores como } \\
\text { "Iombalgia" }\end{array}$ & $\begin{array}{l}\text { Queda da } \\
\text { produtividade }\end{array}$ & $\begin{array}{l}\text { Aquisição de assento } \\
\text { com encosto apro- } \\
\text { priado para o tipo de } \\
\text { tarefa exercida }\end{array}$ & $\begin{array}{l}\text { Pouco recurso } \\
\text { financeiro da } \\
\text { empresa ou } \\
\text { não relevância } \\
\text { ao problema }\end{array}$ \\
\hline \multicolumn{7}{|c|}{ Arquitetural } \\
\hline $\begin{array}{l}\text { Falta de espa- } \\
\text { ços definidos }\end{array}$ & $\begin{array}{l}\text { Local para } \\
\text { o material }\end{array}$ & $\begin{array}{l}\text { Acidente com } \\
\text { materiais e } \\
\text { deformação da } \\
\text { matéria-prima }\end{array}$ & $\begin{array}{l}\text { Acidentes como cor- } \\
\text { tes e perfurações no } \\
\text { corpo do trabalhador }\end{array}$ & $\begin{array}{c}\text { Acidentes físicos } \\
\text { e afastamentos } \\
\text { de trabalhadores. } \\
\text { Despesa com } \\
\text { novos materiais }\end{array}$ & $\begin{array}{l}\text { Adequação do } \\
\text { ambiente com novo } \\
\text { layout }\end{array}$ & $\begin{array}{l}\text { Pouco recurso } \\
\text { financeiro da } \\
\text { empresa ou } \\
\text { não relevância } \\
\text { ao problema }\end{array}$ \\
\hline \multicolumn{7}{|c|}{ Acidentário } \\
\hline $\begin{array}{l}\text { Materiais } \\
\text { expostos em } \\
\text { passagens }\end{array}$ & $\begin{array}{l}\text { Local para } \\
\text { o material }\end{array}$ & $\begin{array}{l}\text { Chapa com can- } \\
\text { tos vivos expostos } \\
\text { na passagem dos } \\
\text { empregados }\end{array}$ & $\begin{array}{l}\text { Acidentes como cor- } \\
\text { tes e perfurações no } \\
\text { corpo do trabalhador }\end{array}$ & $\begin{array}{l}\text { Afastamentos } \\
\text { e queda da } \\
\text { produtividade }\end{array}$ & $\begin{array}{c}\text { Organizar ou cons- } \\
\text { truir novo local para } \\
\text { estocagem desses } \\
\text { produtos }\end{array}$ & $\begin{array}{l}\text { Pouco recurso } \\
\text { financeiro da } \\
\text { empresa ou } \\
\text { não relevância } \\
\text { ao problema }\end{array}$ \\
\hline \multicolumn{7}{|c|}{ Acidentário } \\
\hline $\begin{array}{l}\text { Barreiras nos } \\
\text { acessos aos } \\
\text { extintores de } \\
\text { incêndio }\end{array}$ & $\begin{array}{l}\text { Local para } \\
\text { o material }\end{array}$ & $\begin{array}{l}\text { Desespero que } \\
\text { pode causar negli- } \\
\text { gência no com- } \\
\text { bate ao incêndio }\end{array}$ & Queimaduras, mortes & $\begin{array}{c}\text { Acidentes físicos } \\
\text { e afastamentos } \\
\text { de trabalhadores, } \\
\text { mortes }\end{array}$ & $\begin{array}{l}\text { Organização no local } \\
\text { dos extintores de } \\
\text { incêndio para facilitar } \\
\text { sua utilização }\end{array}$ & $\begin{array}{l}\text { Pouco recurso } \\
\text { financeiro da } \\
\text { empresa ou } \\
\text { não relevância } \\
\text { ao problema }\end{array}$ \\
\hline \multicolumn{7}{|c|}{ Físico-ambiental } \\
\hline $\begin{array}{l}\text { Iluminação } \\
\text { insuficiente }\end{array}$ & $\begin{array}{l}\text { Iluminação } \\
\text { adequada }\end{array}$ & $\begin{array}{l}\text { Esforço extra para } \\
\text { ajustar a visão; } \\
\text { causa sombras, } \\
\text { dificultando } \\
\text { a visão }\end{array}$ & $\begin{array}{l}\text { Cefaleia; fadiga e } \\
\text { lacrimejamento cau- } \\
\text { sado pelo reflexo } \\
\text { direto da luz; lombal- } \\
\text { gias, câimbras e for- } \\
\text { mação de varizes dos } \\
\text { membros inferiores }\end{array}$ & $\begin{array}{l}\text { Afastamentos } \\
\text { e queda da } \\
\text { produtividade }\end{array}$ & $\begin{array}{l}\text { Adequação de ilumi- } \\
\text { nação ao posto de } \\
\text { trabalho regido pelas } \\
\text { normas vigentes }\end{array}$ & $\begin{array}{l}\text { Pouco recurso } \\
\text { financeiro da } \\
\text { empresa ou } \\
\text { não relevância } \\
\text { ao problema }\end{array}$ \\
\hline \multicolumn{7}{|c|}{ Informacional } \\
\hline $\begin{array}{l}\text { Equipamento } \\
\text { em sobre- } \\
\text { posição aos } \\
\text { letreiros } \\
\text { informativos }\end{array}$ & $\begin{array}{l}\text { Locais para } \\
\text { comunica- } \\
\text { ção interna }\end{array}$ & $\begin{array}{l}\text { Falta de com- } \\
\text { preensão ou indi- } \\
\text { ferença com a } \\
\text { comunicação }\end{array}$ & $\begin{array}{l}\text { Descumprimento de } \\
\text { normas internas }\end{array}$ & $\begin{array}{l}\text { Má comunica- } \\
\text { ção entre as che- } \\
\text { fias e queda da } \\
\text { produtividade }\end{array}$ & $\begin{array}{l}\text { Fazer locais adequa- } \\
\text { dos para informação } \\
\text { utilizado recursos cor- } \\
\text { retos de diagramação } \\
\text { para facilitar a leitura }\end{array}$ & $\begin{array}{l}\text { Pouco recurso } \\
\text { financeiro da } \\
\text { empresa ou } \\
\text { não relevância } \\
\text { ao problema }\end{array}$ \\
\hline
\end{tabular}


torno de: $80 \%$ para o teto; 15 a $20 \%$ para o piso; $60 \%$ para a parede (parte alta); $40 \%$ para as divisórias, para a parede (parte baixa) e para o mobiliário ${ }^{15}$.

Quanto ao mobiliário dos postos de trabalho, a norma regulamentadora especifica que, quando o trabalho passa a ser executado na posição sentada, o local deve ser projetado ou adaptado para a posição do trabalhador. Já em relação ao trabalho manual (sentado ou semissentado), as bancadas, mesas, escrivaninhas e os painéis devem proporcionar ao trabalhador condições de boa postura, visualização e operação da tarefa.

No trabalho que necessite da utilização dos pés, além do que foi apontado, os pedais e demais comandos acionados pelos pés devem ter posicionamento e dimensões que possibilitem o fácil alcance, bem como ângulos adequados entre as diversas partes do corpo do trabalhador, em função das características e peculiaridades do trabalhado a ser executado.

Ainda em relação aos assentos a serem utilizados nos postos de trabalhos, eles devem atender, dentre outros, aos seguintes requisitos mínimos de conforto:

- altura ajustável à estatura do trabalhador e à natureza da função exercida;

- características de pouca ou nenhuma contração na base do assento;

- base frontal arredondada;

- encosto com forma levemente lombada.

Outrossim, para as atividades que os trabalhadores devem realizar sentados, a partir da análise ergonômica de trabalho, poderá ser exigido suporte para os pés que se adapte ao cumprimento da forma do trabalhador, enquanto para as atividades realizadas com o trabalhador em pé, devem ser colocados assentos para descanso em locais que possam ser utilizados por todos os trabalhadores durante as pausas. Quanto a isso, Dul e Weerdmeester ${ }^{14}$ afirmam que as posturas sentadas de longa duração podem ser variadas usando diferentes tipos de cadeiras e recomendam alternar as posições sentadas e em pé, de vez em quando.

No tocante aos equipamentos de postos de trabalho, a norma diz também que eles devem ser adequados às características psicofisiológicas dos trabalhadores e à natureza do trabalho a ser executado.

Com ou sem reconhecimento de nexo com o trabalho, uma parcela significativa de pacientes diagnosticados como portadores de distúrbios osteomusculares desenvolve dor crônica e enfrenta importante limitação, ou mesmo incapacidade, para a reinserção produtiva, o que constitui grande desafio para pacientes e médicos e alto custo social e econômico para o país ${ }^{16}$.

Nas atividades que exigem sobrecarga muscular estática ou dinâmica do pescoço, dos ombros e dos membros superiores e inferiores, a partir de análise ergonômica do trabalho, deve-se observar a norma e estabelecer recomendações preventivas. Dul e Weerdmeester ${ }^{14}$ relatam que o trabalho por longos períodos usando as mãos e os braços em posturas inadequadas pode produzir dores nos punhos, cotovelos e ombros.

Conforme Silveira ${ }^{17}$, cabe ao profissional de ergonomia tornar público para a comunidade científica em geral o seu trabalho, fazendo reconhecer aqueles colaboradores e participantes responsáveis pela condução de estudos, projetos e intervenções, que serão objeto de perícias médicas em eventual visita técnica na empresa.

Deve-se lembrar de que nenhuma postura ou movimento repetitivo deve ser mantido por um longo tempo, já que são posições extremamente fatigantes, podendo ocasionar, em longo prazo, lesões nos músculos e nas articulações. Portanto, recomenda-se, para todas as atividades avaliadas, que as posturas estáticas devem ser alternadas com atividades andando, por meio de rodízios periódicos de uma atividade para outra entre os auxiliares de produção, uma vez que eles executam diversas atividades.

Como forma de reduzir o risco de fadiga muscular, indicase, também para todas as atividades avaliadas, que sejam feitas diversas pausas curtas distribuídas ao longo da jornada de trabalho. Portanto, recomendou-se a adoção de pausas de 30 minutos a cada 2 horas de atividade. Nessa pausa deve ser orientada a realização de alongamentos individuais dos braços e das pernas, com o objetivo de aumentar a mobilidade desses segmentos corporais, diminuindo a tensão nos tendões e refletindo na realização das tarefas com maior qualidade e segurança.

Sugere-se também que seja elaborado, com base na avaliação ergonômica do trabalho, um manual de procedimentos para o posto de trabalho dos auxiliares de produção, contemplando cada atividade e as recomendações posturais para a sua realização, bem como o treinamento dos alongamentos a serem realizados na recomendação anterior.

Dadas essas afirmações, a prática da observação contínua diz respeito a requisitos básicos quanto ao bem-estar físico do trabalhador da indústria metalúrgica que devem ser continuamente considerados. 


\section{CONCLUSÕES}

A pesquisa demonstrou a fragilidade das condições de trabalho em uma empresa de São Luís, Maranhão. É importante realizar mudanças, de acordo com a ergonomia, com vistas à garantia de melhores condições de serviço.
A pesquisa propôsum suporteinicialàqueles que querem continuar a pesquisa em ergonomia, podendo fazer o paralelo em suas mais amplas ramificações nos trabalhos dasindústrias metalúrgicas ou, ainda, iniciar um novo tema que aborde intervenções ergonômicas. É importante ressaltar que o trabalho apresentado amplia o canal para o conhecimento na academia, incentivando novos estudantes ao entendimento da profissão eà prática da ergonomia.

\section{REFERÊNCIAS}

1. Federación Internacional de Trabajadores de las Industrias Metalúrgicas (FITIM). Perspectivas de la industria metalúrgica mundial. 2010 [acesso em 2014 nov 21]. Disponível em: <www.imfmetal.org/>

2. Departamento Intersindical de Estatística Estudos Socioeconômicos (DIEESE). Mapeamento do Emprego e Desempenho da Indústria Metalúrgica do Brasil. 2011 [acesso em 2014 nov 21]. Disponível em: <www.cnmcut.org.br/>

3. Soares MM. Atualidades da ergonomia no Brasil e no mundo: uma visão geral. In: ENCONTRO NACIONAL DEERGONOMIA DO AMBIENTE CONSTRUÍDO - ENEAC, 1., 2007, Recife. Anais... Recife: ABERGO, 2007.

4. Vicente KJ. The human factors. New York: Routledge; 2004.

5. Salvendy G. Handbook of human factors and ergonomics. $2^{\text {nd }} e d$. New York: Wiley; 1997.

6. Chapanis A. The chapanis chronicles: 50 years of human factors research, education, and designer. Santa Barbara: Aegean; 1999.

7. William DJ. Conceptualization of risk. In: Karwowsky W. (Org.). International encyclopedia of ergonomics and human factors. $2^{\text {nd }}$ ed. New York: Taylor \& Francis; 2006. (CD-ROM).

8. Brasil. Ministério do Trabalho e Emprego. NR 17: Ergonomia [acesso em 2014 nov 21]. Disponível em: <www.portal.mte.gov.br>

9. Veronesi Júnior JR. Perícia Judicial para Fisioterapeutas. São Paulo: Martinari; 2009.

10. Vidal MCR. Ergonomia na empresa: útil, prática e aplicada. Rio de Janeiro: Virtual Científica; 2002.
11. Wisner AA. Inteligência no trabalho: Textos selecionados de ergonomia. 1a ed. São Paulo: Fundacentro; 1993.

12. Soares MM. Apostila da disciplina: introdução à ergonomia. Curso de Especialização em Ergonomia. Maranhão: Universidade Federal do Maranhão; 2006.

13. Martins MV, Leite ICG. Aspectos nutricionais, antropometria e ingestão hídrica de trabalhadores metalúrgicos. Rev Bras Med. 2010;8(2):82-8.

14. Dul J, Weerdmeester B. Ergonomia prática. São Paulo: Edgard Blucher; 2004.

15. Marques A, Tavares E, Souza J, Magalhães JA, Léllis J. A Ergonomia como um fator determinante no bom andamento da produção: um estudo de caso. Rev Anagrama. 2010;4(1):1-14.

16. Azambuja MIR. Dor osteomuscular crônica: problema de saúde pública que requer mais prevenção e nova abordagem clínica e previdenciária? Rev Bras Med Trab. 2012;10(1):129-31.

17. Silveira D. Apostila da disciplina: deontologia da ergonomia. Curso de Especialização em Ergonomia. Maranhão: Universidade Federal do Maranhão; 2009

Endereço para correspondência: Maria do Desterro Soares Brandão Nascimento Universidade Federal do Maranhão - Avenida dos Portugueses, 1966, Bacanga, Prédio do CCBS, Bloco 3, Sala 3A - Cidade Universitária - CEP: 65080-805 -

São Luís (MA), Brasil - E-mail: marcosantonio456@hotmail.com 